\title{
Identification of the relationship between Chinese Adiantum reniforme var. sinense and Canary Adiantum reniforme
}

\author{
Ai-Hua Wang ${ }^{1,2}$, Ye Sun ${ }^{1}$, Harald Schneider ${ }^{3}$, Jun-Wen Zhai ${ }^{4}$, Dong-Ming Liu', Jin-Song Zhou ${ }^{5}$, Fu-Wu Xing ${ }^{1}$,
} Hong-Feng Chen ${ }^{1 *}$ and Fa-Guo Wang ${ }^{1 *}$

\begin{abstract}
Background: There are different opinions about the relationship of two disjunctively distributed varieties Adiantum reniforme L. var. sinense Y.X.Lin and Adiantum reniforme L. Adiantum reniforme var. sinense is an endangered fern only distributed in a narrowed region of Chongqing city in China, while Adiantum reniforme var. reniforme just distributed in Canary Islands and Madeira off the north-western African coast. To verify the relationship of these two taxa, relative phylogenetic analyses, karyotype analyses, microscopic spore observations and morphological studies were performed in this study. Besides, divergence time between $A$. reniforme var. sinense and A. reniforme var. reniforme was estimated using GTR model according to a phylogeny tree constructed with the three cpDNA markers atpA, atpB, and rbcL.
\end{abstract}

Results: Phylogenetic results and divergence time analyses-all individuals of $A$. reniforme var. sinense from 4 different populations (representing all biogeographic distributions) were clustered into one clade and all individuals of $A$. reniforme var. reniforme from 7 different populations (all biogeographic distributions are included) were clustered into another clade. The divergence between $A$. reniforme var. reniforme and A. reniforme var. sinense was estimated to be 4.94 (2.26-8.66) Myr. Based on karyotype analyses, A. reniforme var. reniforme was deduced to be hexaploidy with $2 n=180, X=30$, while $A$. reniforme var. sinense was known as tetraploidy. Microscopic spore observations suggested that surface ornamentation of $A$. reniforme var. reniforme is psilate, but that of $A$. reniforme var. sinense is rugate. Leaf blades of $A$. reniforme var. sinense are membranous and reniform and with several obvious concentric rings, and leaves of $A$. reniforme var. reniforme are pachyphyllous and coriaceous and are much rounder and similar to palm.

Conclusion: Adiantum reniforme var. sinense is an independent species rather than the variety of Adiantum reniforme var. reniforme. As a result, we approve Adiantum nelumboides X. C. Zhang, nom. \& stat. nov. as a legal name instead of the former Adiantum reniforme var. sinense. China was determined to be the most probable evolution centre based on the results of phylogenetic analyses, divergence estimation, relative palaeogeography and palaeoclimate materials.

Keywords: Chromosome numbers, cpDNA, Flow cytometry, Molecular clock dating, Morphological characters, Phylogenetic position, Relationship identification, SEM observation

\footnotetext{
* Correspondence: h.f.chen@scbg.ac.cn; wangfg@scib.ac.cn

'Key Laboratory of Plant Resources Conservation and Sustainable Utilization,

South China Botanical Garden, Chinese Academy of Sciences, Guangzhou

510650, China

Full list of author information is available at the end of the article
} 


\section{Background}

Adiantum reniforme L. var. sinense Y.X.Lin (Chinese name "He ye jin qian cao") was first discovered in Chongqing city in China in 1978 [1]. It was published in Acta Phytotaxonomica Sinica as a variety of Adiantum reniforme L. because of their similar morphological characters in 1980. It is only distributed along the Yangtze River from Shizhu County to the Wanzhou District of Chongqing, which stretches for almost 100 kilometres through Xi-tuo, Xinxiang, Wu-ling, Chang-ping and other places [2-4]. It has a narrow distribution zone and an endangered status. $A$. reniforme var. sinense was listed as a class II protected fern in China [2]. The plant is known to have medicinal uses including heat-clearing and detoxifying, promoting diuresis and relieving stranguria, curing icteric hepatitis and stones [5]. As a result, the plant has been over-collected by local people. Additionally, the construction of the Three Gorges Dam from 1993 to 2009 caused destruction of habitats and reduced its population size, which reduced gene flow among populations [6]. Many studies have been conducted to protect $A$. reniforme var. sinense from extinction. These studies included field habitat investigations [2], the use of spore propagation technology [7] and increases in population gene diversity $[6,8,9]$. A reniforme var. sinense was previously shown to be tetraploid $(2 \mathrm{n}=120, \mathrm{X}=30)$ in Lin YX [10]. Scanning electron microscopy (SEM) analysis of $A$. reniforme var. sinense suggested that its spores are actinomorphic and trilete with polar surface triangles. Additionally, the equatorial surface is semicircular or super-semicircular, and the surface ornamentation is psilate [11]. Adiantum belongs to the family Pteridaceae, although different opinions exist regarding whether Adiantum is monophyletic or paraphyletic with vittarioid ferns [12-17]. A phylogenetic tree of Chinese Adiantum was constructed using five cpDNA primers for the following genes: $\operatorname{atp} \mathrm{A}, \operatorname{atp} \mathrm{B}, \operatorname{rbcL}, \operatorname{trn} \mathrm{L}-\mathrm{F}$ and trnS. This analysis indicated that Adiantum was monophyletic and $A$. reniforme var. sinense was closely related to Adiantum Ser. Venusta, which was established by Ching Renchang in Flora Republicae Popularis Sinicae, Tomus 3(1) [18].

There are a limited number of reports of $A$. reniforme var. reniforme. The first specimens were collected in Madeira, and it was first published in Species Plantarum by Linnaeus in 1753 . The plant is found in the Canary Islands and Madeira off the north-western African coast. Manton [19] considered $A$. reniforme var. reniforme as decaploid $(2 \mathrm{n}=300, \mathrm{X}=30)$ after her study on the specimens kept in Kew garden but collected in Madeira and Tenerife. In 1985, Mary Gibby restudied ploidy and the chromosomes of materials collected in the Canary Island and suggested that it was tetraploid $(2 \mathrm{n}=120, \mathrm{X}=30)$. However, there is no photographic record of this result. Subsequent studies have demonstrated that ploidy levels of all ferns in the Canary Islands are no more than hexaploid [20]. Consequently, the ploidy of $A$. reniforme var. reniforme is controversial, and the differences in chromosome number between the Canary population and the Madeira population are unclear.

There are similar morphological characters between $A$. reniforme var. sinense and $A$. reniforme var. reniforme. So, it seems reasonable that they are varieties. However, the China-Canary distribution disjunction of these two taxa makes their relationships doubtful. Zhang XC [21] treated $A$. reniforme var. reniforme as an independent species in the book "Lycophytes and ferns of China" but without explanation. As described above, the spore morphology, karyotype analysis and phylogenetic analysis of $A$. reniforme var. reniforme are currently unknown. Because of the limited morphological characters of these two taxa, for example, only one single leaf blade with one petiole, it is not convictive for the treatment that they were varieties between each other just based on their limited morphological characters (see Figure 1). Additional studies are required to determine whether $A$. reniforme var. sinense is a variety or an independent species. To make the taxonomy relationship between $A$. reniforme var. sinense and $A$. reniforme var. reniforme clear and deduce mechanisms of the intercontinental disjunction, we have analysed 7 populations consisting of almost 96 individuals of $A$. reniforme var. sinense from China and 8 populations consisting of almost 164 individuals of $A$. reniforme var. reniforme from Canary and Madeira.

\section{Methods}

\section{Materials}

In this study, 24 individuals from 11 populations of both the Adiantum reniforme var. reniforme and $A$. reniforme var. sinense representing all biogeographic distributions were sampled and sequenced. The 31 species of Adiantum and Vittaria flexuosa (outgroup) were downloaded from GenBank to construct a phylogeny tree of Adiantum with the combined cpDNA markers $\operatorname{atp} \mathrm{A}, \operatorname{atp} \mathrm{B}, \operatorname{trn} \mathrm{L}-\mathrm{F}$ and trnS. Furthermore, three plastid genes $(r b c \mathrm{~L}$, atp $\mathrm{A}$, and $a t p \mathrm{~B})$ from 24 outgroup species were downloaded to test the divergence time of Adiantum reniforme var. reniforme and $A$. reniforme var. sinense. All taxa included in this study, voucher information and collection sites are listed in Additional file 1 and Addition file 2.

\section{DNA extraction, amplification and sequencing}

Total DNA was extracted from $20 \mathrm{mg}$ silica-gel-dried leaf material using a modified CTAB DNA extraction protocol [22]. The atpA gene was amplified with primers "ESATPF412F"and"ESTRNR46F” [23]. "ESATB172F” and "ESATPE45R" were used for amplifying and sequencing the $\operatorname{atp} B$ gene [14]. " $1 \mathrm{~F}$ " and "1379R" were used to 


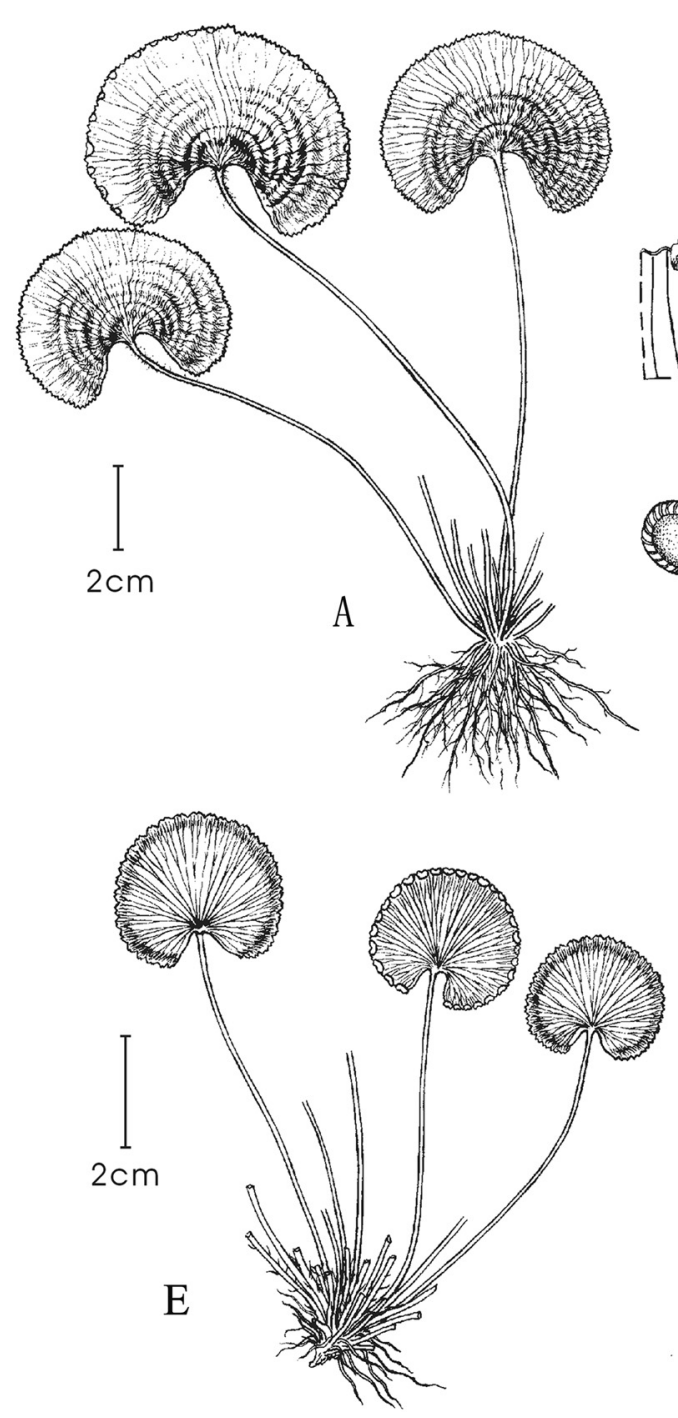

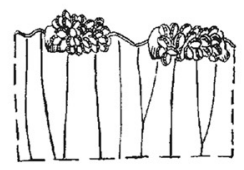

$\mathrm{B}$

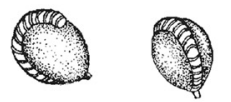

$\mathrm{C}$

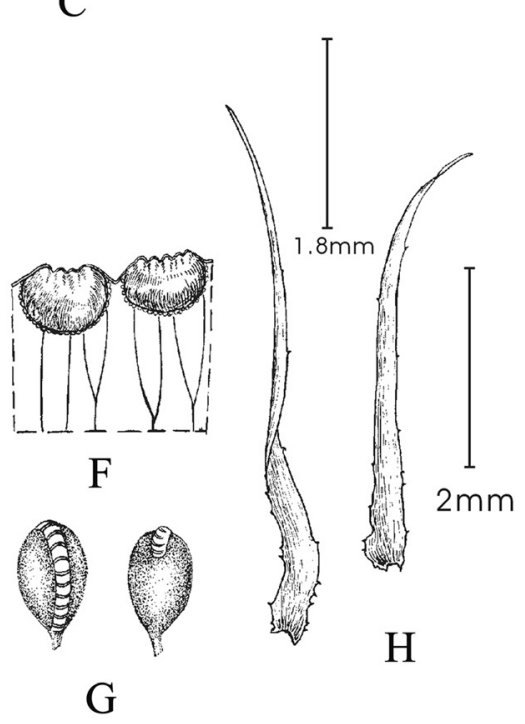

Figure 1 Morphological characters of $A$. reniforme var. sinense and A. reniforme var. reniforme. A, B, C, and D represent the leaf, sporangiorus, sporangium and scales of A. reniforme var. sinense, respectively. $\mathbf{E}, \mathbf{F}, \mathbf{G}$, and $\mathbf{H}$ represent the related leaf, sporangiorus, sporangium and scales of A. reniforme var. sinense, respectively.

amplify and sequence the $r b c \mathrm{~L}$ gene [24]. The trnL-F region was amplified and sequenced with primers "p1" and "f" [25,26]. Primers "trnS" [27] and "rps4.5" [28] were used to amplify and sequence the rps4-trnS region. All amplifications were performed in a $30-\mu \mathrm{L}$ reaction mixture. The PCR reactions contained the following reagents: $1.0-2.4 \mu \mathrm{L}$ of each primer (5p), 17-60 ng sample DNA, $1.5 \mathrm{U}$ of Taq DNA polymerase, $10 \times$ buffer (including $\left.\mathrm{Mg}^{2+}\right), 0.25 \mathrm{mmol} \cdot \mathrm{L}^{-1} \mathrm{dNTP}$, and ultrapure water $\left(\mathrm{ddH}_{2} \mathrm{O}\right)$. The $\operatorname{atp} \mathrm{A}$ and $\operatorname{atp} \mathrm{B} 30-\mu \mathrm{L}$ reaction mixtures were incubated at $95^{\circ} \mathrm{C}$ for $10 \mathrm{~min}$, cycled 35 times $\left(95^{\circ} \mathrm{C}\right.$ for $1 \mathrm{~min}, 50^{\circ} \mathrm{C}$ for $1 \mathrm{~min}$, and $72^{\circ} \mathrm{C}$ for $100 \mathrm{~s}$ ), followed by a final extension for $10 \mathrm{~min}$ at $72^{\circ} \mathrm{C}$. The $r b c \mathrm{~L}$ and $t r n \mathrm{~L}-\mathrm{F}$ PCR reactions were incubated at $95^{\circ} \mathrm{C}$ for $3 \mathrm{~min}$, cycled 35 times $\left(95^{\circ} \mathrm{C}\right.$ for $1 \mathrm{~min}, 51^{\circ} \mathrm{C}$ for $1 \mathrm{~min}$, and $72^{\circ} \mathrm{C}$ for $80 \mathrm{~s}$ ), followed by a final extension for $10 \mathrm{~min}$ at $72^{\circ} \mathrm{C}$. The rps4trnS PCR reactions were incubated at $95^{\circ} \mathrm{C}$ for $3 \mathrm{~min}$, cycled 35 times $\left(94^{\circ} \mathrm{C}\right.$ for $30 \mathrm{~s}, 58^{\circ} \mathrm{C}$ for $45 \mathrm{~s}$, and $72^{\circ} \mathrm{C}$ for $80 \mathrm{~s}$ ), followed by a final extension for $10 \mathrm{~min}$ at $72^{\circ} \mathrm{C}$. The PCR products were purified and sequenced with an ABI 3730XL by Majorbio Company.

\section{Phylogenetic analyses}

The sequences were assembled with Sequencher 4.14 and then adjusted manually through Bioedit v.7.1.3 [29] and aligned using the program Clustal $\mathrm{X}$ version 2.0 [30]. Phylogenetic trees of each individual and the combined markers (atp $\mathrm{A}, \operatorname{atp} \mathrm{B}, r b c \mathrm{~L}, t r n \mathrm{~L}-\mathrm{F}$, and $r p s 4-t r n \mathrm{~S})$ were constructed using maximum parsimony (MP) and Bayesian Markov chain Monte Carlo (MCMC) inference. 
The maximum parsimony analyses were performed with PAUP* 4.0b10 [31], treating gaps as missing data and using the heuristic search options with 1000 random replicates and tree-bisection-reconnection (TBR) branch swapping. All characteristics were unordered and equally weighted. For Bayesian analyses, MrModeltest2 (v2.3; [32]) based on the Akaike information criterion (AIC) was used to identify the best-fit molecular evolution model for each of the DNA markers. We constructed Bayesian trees using MrBayes 3.1 [33] with the best-fit model GTR + I + G. Trees were generated for 1,000,000 generations, sampling every 100 generations. Four chains were used with a random initial tree. For each of the individual data partitions and the combined dataset, the first 2500 sample trees were discarded as burn-in to ensure that the chains reached stationarity. Nodes receiving bootstrap support (BS) of $<70 \%$ in the MP analyses or PP of $<0.95$ in the $\mathrm{BI}$ analyses were not considered to be well supported.

\section{Molecular clock dating}

Bayesian molecular dating studies were performed with the combined dataset of $r b c \mathrm{~L}$, atp A and $a t p B$. Sequences of 24 outgroup species were downloaded from NCBI. The divergence time estimation of each clade in Adiantum and their credibility intervals were implemented in BEAUTI / BEAST 1.7.4 [34]. The BEAST analyses were performed with the GTR model, the uncorrelated relaxed lognormal clock model and the coalescent exponential growth tree. We used the $65.5 \pm 0.3 \mathrm{Myr}$, which was the crown of the ceratopteridoids clade [35], as the calibration point. Posterior distributions of parameters were approximated using three independent MCMC analyses of 20,000,000 generations with $10 \%$ burn-in. Convergence was examined using Tracer 1.5 [36].

\section{Karyotype analysis}

To deduce the ploidy levels of $A$. reniforme var. reniforme, A. reniforme var. sinense was used as an internal standard because of its clear sporophytic chromosomes $(2 \mathrm{n}=120, X=30)$, as displayed in Lin YX [10]. There were 32 sporophytic materials from different populations of both taxa examined by flow cytometric analyses to confirm the accuracy of ploidy levels for A. reniforme var. reniforme (Table 1). The leaves have membranous and hard leaf blades, so young and fresh blades spreading from circinate leaves were used. Small pieces of plant leaves were chopped with a double-edged razor in a Petri dish containing $0.4 \mathrm{~mL}$ mixed buffer (including ice-cold Otto buffer combined with DAPI fluorochrome, as patented by Partec Comneruim). Then, an additional $1.6 \mathrm{~mL}$ of buffer was mixed with the cells in the Petri dish and the cells were filtered through a $30-\mu \mathrm{m}$-mesh filter into a 5 - $\mathrm{mL}$ cytometry tube. The tube was incubated in the dark at room temperature for 5-10 min. Each sample was analysed on a flow cytometer (Cyflow Space, Partec) equipped with a high-pressure mercury arc lamp for UV excitation. For each sample, a minimum of 2,000 nuclei were analysed. The fluorescence peaks and relative fluorescence intensity were analysed by the software Flomax.

\section{SEM observation}

For SEM analysis, mature spores from different populations were dispersed on stubs directly after being collected. The spores were gold-coated in a JFC-1600 Auto Fine Coater and observed using a JEOL JSM-6360LV Scanning Electron Microscope at $25 \mathrm{kV}$ at the South China Botanical Garden, Chinese Academy of Sciences. The spore mean sizes of 7 populations of A. reniforme var. sinense and 7 populations of $A$. reniforme var. reniforme were measured by Smile View software (20 spores per population), and a scatter diagram was made with SPSS. The descriptive terminology in Spores of Polypodiales (Filicales) from China [11] and Plant identification terminology: An illustrated glossary [37] was followed.

\section{Results}

\section{Phylogenetic and molecular divergence time analyses}

The topologies derived from analyses of the individual datasets were similar to those obtained from the combined data. Therefore, we emphasised the results of the combined data. The sequences of 23 Chinese species and 8 foreign species of Adiantum and Vittaria flexuosa (outgroup) were downloaded from GenBank. The combined 4-marker $(\operatorname{atp} \mathrm{A}, \operatorname{atp} \mathrm{B}, \operatorname{trn} \mathrm{L}-\mathrm{F}$ and $r p s 4-t r n S)$ dataset included 56 taxa and consisted of 5,210 nucleotides, of which 1961 were variable (37.6\%) and 1,468 were phylogenetically informative (28.2\%). Rooted with the specified outgroup Vittaria flexuosa, the MP analysis on the combined 4-marker dataset yielded one maximally parsimonious tree of 3,911 steps, a consistency index (CI) of 0.6423 , and a retention index (RI) of 0.8944 . The tree obtained from the BI analyses had similar topology as the MP strict consensus tree (Figure 2).

All individuals of $A$. reniforme var. sinense from different populations were clustered into one clade, and all individuals of $A$. reniforme var. reniforme from different populations were clustered into another clade (Figure 2). Our analysis strongly supported that Canary Islands and Madeira A. reniforme var. reniforme was sister to Chinese $A$. reniforme var. sinense (1.0/100). The genetic distance (GD) between $A$. reniforme var. reniforme and A. reniforme var. sinense was calculated by constructing $\mathrm{NJ}$ trees using Mega5.0 based on the combined 4-marker data. Compared with the GD between A. caudatum and A. malesianum (GD $=0.004 \pm 0.001$ ) and the distance between $A$. flabellulatum and $A$. induratum $(\mathrm{GD}=0.008 \pm 0.002)$, the 
Table 1 Relative fluorescence intensity (DAPI measurements) for the $A$. reniforme var. sinense and $A$. reniforme var. reniforme, summarised by the phytogeographic regions

\begin{tabular}{|c|c|c|c|c|c|c|}
\hline Taxon & Ploidy level & Accession number & Region & $\begin{array}{l}\text { Relative } \\
\text { fluorescence } \\
\text { intensity }\end{array}$ & $\begin{array}{l}\text { Relative fluorescence } \\
\text { intensity (mean } \pm \text { s.d.) }\end{array}$ & $\begin{array}{l}\text { Overall } \\
\text { mean }( \pm \text { s.d.) }\end{array}$ \\
\hline \multirow[t]{3}{*}{ A.reniforme var. sinense } & $4 X$ & WAH009 & xi-tuo, shi zhu, China & 62.06 & $65.44 \pm 3.59$ & $65.44 \pm 3.59$ \\
\hline & & WAH007 & xi-tuo, shi zhu, China & 65.06 & & \\
\hline & & WAH003 & xi-tuo, shi zhu, China & 69.2 & & \\
\hline \multirow[t]{21}{*}{ A.reniforme var. reniforme } & $?$ & LPCG002 & Cubo de la Galga, La Palma & 103.09 & $97.78 \pm 4.06$ & \\
\hline & & LPCG009 & Cubo de la Galga, La Palma & 100.88 & & \\
\hline & & LPCG011 & Cubo de la Galga, La Palma & 99.42 & & \\
\hline & & LPCG003 & Cubo de la Galga, La Palma & 90.45 & & \\
\hline & & LPCG004 & Cubo de la Galga, La Palma & 96.77 & & \\
\hline & & LPCG001 & Cubo de la Galga, La Palma & 95.92 & & \\
\hline & & LPCGO14 & Cubo de la Galga, La Palma & 97.94 & & \\
\hline & & LPB023 & Bermúdec, La Palma & 82.18 & $84.11 \pm 2.96$ & \\
\hline & & LPB006 & Bermúdec, La Palma & 80.99 & & \\
\hline & & LPB007 & Bermúdec, La Palma & 86.83 & & \\
\hline & & LPB010 & Bermúdec, La Palma & 86.43 & & \\
\hline & & TBI001 & Barranco del Infierno, Tenerife & 95.74 & $92.75 \pm 6.85$ & \\
\hline & & TBI011 & Barranco del Infierno, Tenerife & 97.49 & & \\
\hline & & TBI014 & Barranco del Infierno, Tenerife & 99 & & \\
\hline & & TBI017 & Barranco del Infierno, Tenerife & 88.89 & & \\
\hline & & TBIO05 & Barranco del Infierno, Tenerife & 82.64 & & \\
\hline & & TPH008 & Punta del Hidalgo, Tenerife & 97.32 & & \\
\hline & & TPH021 & Punta del Hidalgo, Tenerife & 93.34 & & \\
\hline & & TPH010 & Punta del Hidalgo, Tenerife & 104.57 & & \\
\hline & & TPH003 & Punta del Hidalgo, Tenerife & 84.62 & & \\
\hline & & TPH0017 & Punta del Hidalgo, Tenerife & 86.86 & $93.34 \pm 8.06$ & $92.92 \pm 7.24$ \\
\hline
\end{tabular}

value between $A$. reniforme var. reniforme and $A$. reniforme var. sinense $(\mathrm{GD}=0.011 \pm 0.003)$ was much longer.

The divergence between A. reniforme var. reniforme and $A$. reniforme var. sinense was estimated to be 4.94 (2.26-8.66) Myr, while A. flabellulatum and A. induratum were dated to diverge 4.06 (1.25-7.80) Myr ago (see Figure 3).

\section{Chromosome analysis}

The ploidy level of A.reniforme var. reniforme was estimated by comparison with the known tetraploidy A. reniforme var. sinense. Based on DAPI staining, 21 accessions of $A$. reniforme var. reniforme showed relative fluorescence intensities of $92.92 \pm 7.24$, and 3 accessions of the internal standard A. reniforme var. sinense showed relative fluorescence intensities of $65.44 \pm 3.59$ (Table 1). We deduced that $A$. reniforme var. reniforme was hexaploidy with $2 \mathrm{n}=$ $180, X=30$ because the relative fluorescence intensity of the $A$. reniforme var. reniforme accessions was approximately 1.5 -fold higher than the $A$. reniforme var. sinense accessions. The chromosome number of $A$. reniforme var. sinense was determined to be $2 n=120, X=30$ [10]. The flow cytometry histograms of both plants are shown in Figure 4 (left).

SEM observation and morphological character differences The spore shapes of both taxa are tetrahedric and are similar in polar and equatorial views. However, the spores are clearly different with respect to surface ornamentation. The spores are actinomorphic and trilete with polar surface triangles, and the equatorial surface is semicircular or super-semicircular. The surface ornamentation of $A$. reniforme var. reniforme is psilate, while that of $A$. reniforme var. sinense is rugate (see Figure 4). The mean sizes of 7 populations of $A$. reniforme var. sinense were $37.1 \pm 3.7 \mu \mathrm{m}$, which is shorter than the 7 populations of $A$. reniforme var. reniforme $(47.8 \pm 3.9 \mu \mathrm{m})$. The spore equatorial axis sizes of Adiantum vary from 32 to $55 \mu \mathrm{m}$ [11], and our findings are consistent with these data. 


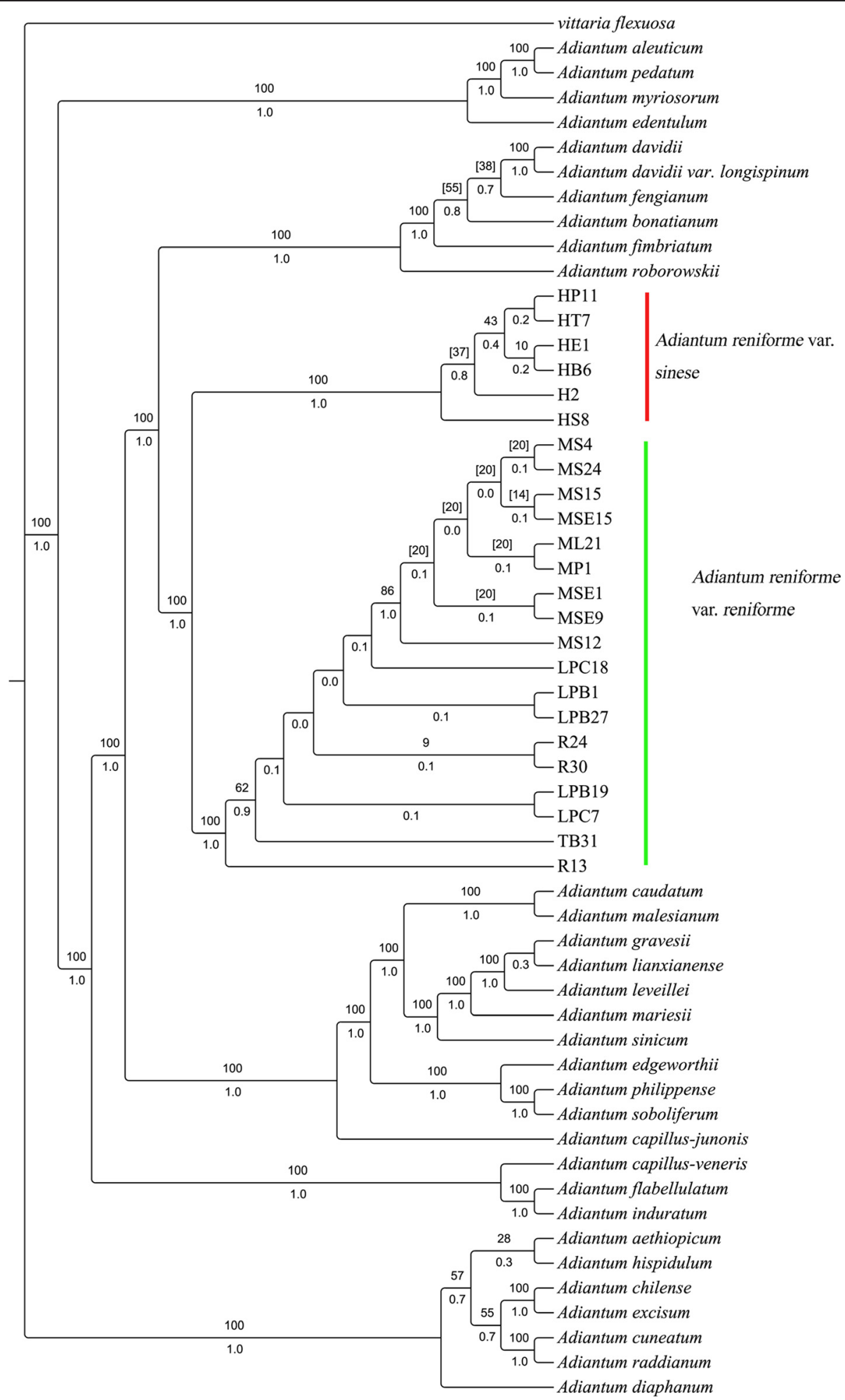

Figure 2 Strict consensus tree of two maximally parsimonious trees derived from the analysis of the plastid atpA, atpB, $\operatorname{trnL}-\mathrm{F}$, and rps4-trnS sequences (tree length $=\mathbf{3 , 9 1 1}$ steps, $\mathbf{C l}=\mathbf{0 . 6 4 2 3}$, and $\mathbf{R I}=\mathbf{0 . 8 9 4 4}$ ). The bootstrap values for 1,000 replicates are shown above the lines, and the Bayesian posterior probabilities are shown below the lines. Front alphabets of HP11, HT7, R13 are the short names of different populations of these two taxa, and the latter numbers represent single individuals. 


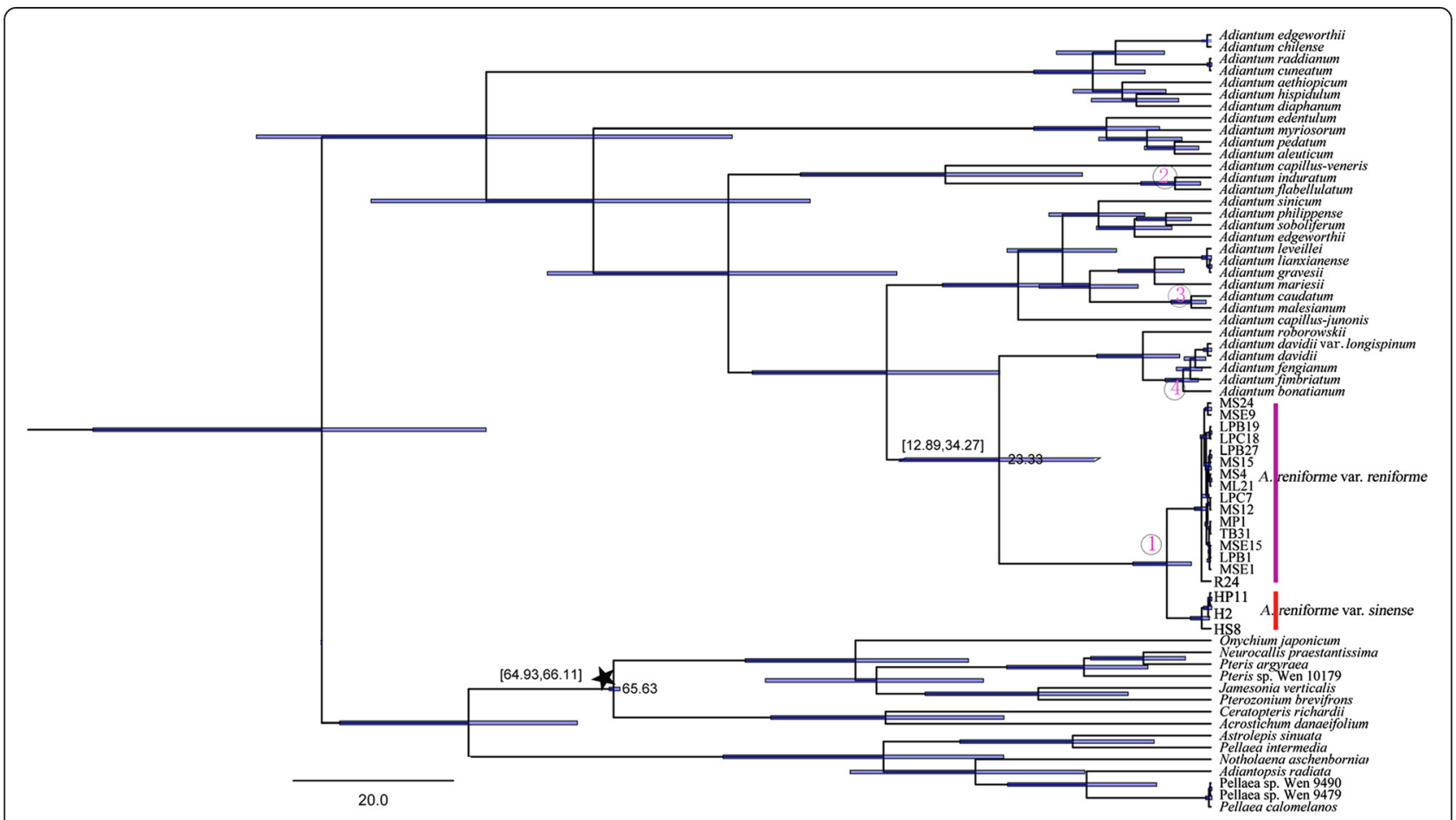

Figure 3 Chronogram of Adiantum inferred from BEAST with combined sequences (atpA, atpB and $r b c \mathrm{~L})$. The calibration scheme is indicated with black asterisks. Node 1: A. reniforme var. reniforme and A. reniforme var. sinense; Node 2: A. flabellulatum and A. induratum

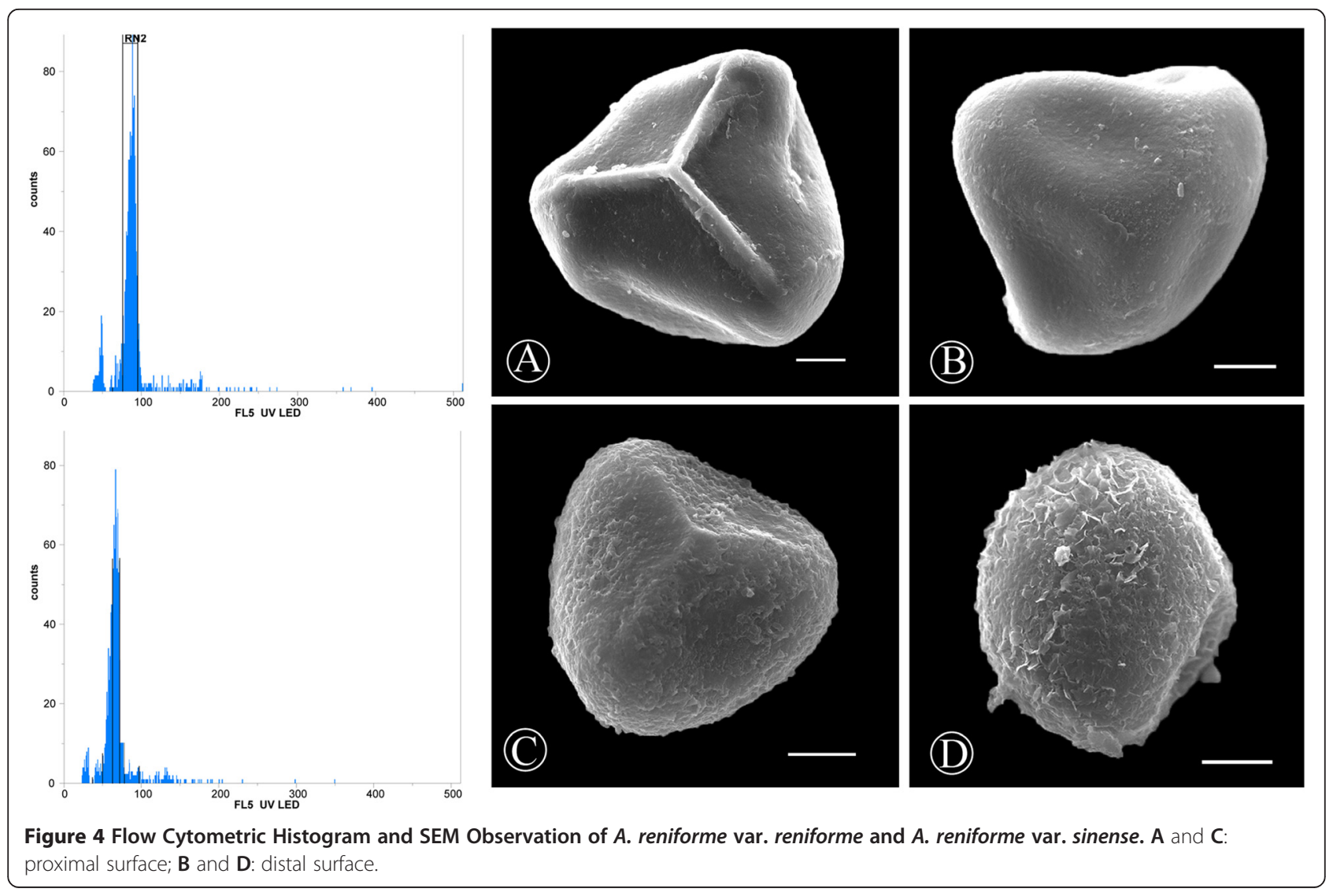


The morphological characters of these two taxa are obviously different. The leaf blades of $A$. reniforme var. sinense are membranous and reniform. Each blade has several concentric rings and yellowish-brown scales. The leaves of $A$. reniforme var. reniforme are pachyphyllous and coriaceous and are much rounder and similar to palm. The leaves lack any concentric rings and have deep brown scales (see Figure 1).

\section{Discussion}

Relationship between $A$. reniforme var. reniform and $A$. reniforme var. asariforme

The Canary Islands A. reniforme var. reniforme was determined to be hexaploid in this study based on flow cytometric analyses of sporophytic material. An additional experiment was performed to determine chromosome numbers with conventional squashes of root tip cells but failed because of the huge numbers and crowded chromosomes. Thus, the chromosomes could not be counted using light microscopy.

The ploidy level of $A$. reniforme var. reniforme is the same as $A$. reniforme var. asariforme if the description in Flora Republicae Popularis Sinicae, 3(1) [5] is correct. According to Flora Republicae Popularis Sinicae, 3(1), A. reniforme var. asariforme is another variety of $A$. reniforme var. reniforme and is only distributed in South Africa, Madagascar, and Mauritius. Its pachyphyllous and coriaceous leaves have deep brown scales that contain tight and slender white hairs on both surfaces of leaves. The taller and stronger plant size and its hexaploidy are considered the major differences from $A$. reniforme var. sinense. However, taller and stronger plants of $A$. reniforme var. reniforme are found in fields in La Palma. Its leaves are also pachyphyllous and coriaceous and have deep brown scales. The leaf shape is very similar to the leaf of $A$. reniforme var. asariforme based on comparisons of their respective specimens. Therefore, it is reasonable that researchers have treated $A$. reniforme var. asariforme as a variety of $A$. reniforme var. reniforme [38]. Tardieu-Blot claimed that $A$. reniforme var. asariforme was conspecific with $A$. reniforme var. reniforme [20]. Further evidence is required to clearly define the relationship between these two varieties.

\section{Evolution of intercontinental disjunctions between Chinese $A$. reniforme var. sinense and Canary $A$. reniforme var. reniforme}

Three issues have to be discussed to explain the evolution of China-Madagascar-Canary intercontinental disjunctions. The first issue is the original centre of these three taxa. Second, how did the spores spread between each location? Finally, what is the genesis evolution and phylogenetic status of ser. Reniformia in Adiantum and Pteridaceae?
There are three probable original centres: China; Madagascar or South Africa; the Canary Islands or the western Mediterranean. According to our phylogenetic analysis and molecular divergence estimation results, China is speculated to be the most probable centre. There is strong evidence showing that Chinese A. reniforme var. sinense is sister to Canary A. reniforme var. reniforme (BP100; PP1.0; Figure 3). Clades of these two species together form ser. Reniformia [5], which has morphological synapomorphies of simple and kidneyshaped blades and clustered short-creeping rhizomes. Ser. Reniformia is suggested to be monophyletic and is sister to Ser. Venusta (Figure 3), which consists of 10 species and 4 varieties only distributed in Chinese temperate regions. The divergence between $A$. reniforme var. reniforme and $A$. reniforme var. sinense was estimated to be 4.94 (2.26-8.66) Myr in the Pliocene, and ser. Reniformia and Ser. Venusta was estimated to diverge in 23.33 (12.89-34.27) Myr in the Miocene. These results indicated that Ser. Reniformia and Ser. Venusta had a common ancestor at least 23.33 Myr ago but diverged later. The divergence may be related to the intense uplift of the Qinghai-Tibet plateau in the Neocene [39]. The average altitude of the Qinghai-Tibet plateau may have reached $2000 \mathrm{~m}$ at $22 \mathrm{Myr}$ [40], during which the landform diversity of the Qinghai-Tibet plateau and climate aridification may have led to the divergence of ser. Reniformia from Ser. Venusta in China. The Himalayas uplifted rapidly 5.4-2.7 Myr [41], and A. reniforme var. reniforme diverged from $A$. reniforme var. sinense 4.94 (2.26-8.66) Myr. These results indicate that the divergence of the two species may be closely related to the rapid uplift of the Himalayas. Paleomonsoon had existed in China in the Eogene and intensified with the uplift of the Qinghai-Tibet plateau in the Neocene [42]. Northwestern Eurasia high pressure centres have passed through Southeast Asian nations such as China and India to the Indian Ocean since the Miocene [40,42]. The long distance dispersal of ferns is more common than seed plants because ferns are dispersed by small, windblown spores that are produced in very large numbers and are capable of travelling thousands of kilometres [43-45]. Thus, it was very possible for spores of Chinese $A$. reniforme var. sinense to reach the Indian Ocean and Madagascar through winter monsoons and other general atmosphere circulation in winter. Spores of $A$. reniforme var. sinense in Madagascar also can get back to China through summer southwest monsoons from the Southern Indian Ocean. However, gene flow was hindered by the high altitude caused by the rapid uplift of the Himalayas in the Pliocene, which caused speciation over time. If China was the origin centre of A. reniforme, the dispersal sequence would be as follows: China to Madagascar and then to Canary. 
The Canary Islands consist of seven volcanic islands, namely El Hierro, La Palma, La Gomera, Tenerife, Gran Canaria, Fuerteventura, and Lanzarote (from west to east, respectively), located off the north-western African coast. They formed by multiple volcanic episodes [46-48] but showed different evolutionary histories [49]. The western islands of La Palma, El Hierro, and Tenerife are the younger archipelago and are still in their shield stage, which began at most 7.5 Myr ago. The oldest island Fuerteventura began its shield stage 20.6 Myr ago [50]. A fossil of A. reniforme var. reniforme was discovered in Meximieux near Lyons in the Rhone Valley in Europe [20]. Thus, the Canary Islands may be glacial refugia of $A$. reniforme var. reniforme in Quaternary.

\section{Conclusions}

Adiantum reniforme var. sinense is an independent species rather than a variety of $A$. reniforme var. reniforme based on morphological differences, spore observations, chromosome analyses, phylogeny research of the genus Adiantum and molecular divergence estimations. Our data are different from Lin YX [1] but in accordance with treatment of Zhang XC [21]. The name Adiantum nelumboides X. C. Zhang should be applied to the Chinese taxon as a legal name and the commonly used name for A. reniforme var. sinense will be treated as a synonym. China is deduced to be the most probable evolution centre of ser. Reniformia, and the divergence between A. reniforme var. sinense and A. reniforme var. reniforme may be related to the intense uplift of the Qinghai-Tibet plateau in the Neocene. The Canary Islands and Madeira were probably glacial refugia of $A$. reniforme var. reniforme in the Quaternary, based on the fossil evidence found in Meximieux near Lyons in the Pliocene.

\section{Availability of supporting data}

The data sets supporting the results of the article are available in GenBank under accession numbers KJ742731KJ742799 and KJ779969-KJ780019. All of the phylogenetic sequence data in this study are deposited in GenBank (National Center for Biotechnology Information) with the link http://www.ncbi.nlm.nih.gov/nuccore/.

\section{Additional files}

Additional file 1: Table S1. Voucher information and GenBank accession numbers for taxa used in the phylogenetic study on Adiantum.

Additional file 2: Table S2. Samples examined in the study to estimate divergence times.

\section{Competing interests}

The authors declare that they have no competing interests.

\section{Authors' contributions}

AHW carried out the molecular phylogeny study and microscopic spore observations and flow cytometry, participated in data analysis and drafted the manuscript; YS conducted the data analysis, and contributed to the supervision and discussion of the research; HS and JWZ revised the manuscript; DML, JSZ contributed to collect part materials; HFC and FWX provided plant samples and contributed to the supervision of the research; FGW provided plant samples, performed morphological studies, conducted interpretation for the data and results and discussions, and contributed to the supervision of the research. All authors read and approved the final manuscript.

\section{Acknowledgements}

The authors thank Senior Engineer Xiao-Ying HU (South China Botanical Garden, Chinese Academy of Sciences, Guangzhou, China) for her help with SEM studies, Qing-Wen ZENG, Hui YU (South China Botanical Garden, Chinese Academy of Sciences, Guangzhou, China) and Jin-Song ZHOU (College of Chinese Traditional Medicine, Guangzhou University of Chinese Medicine, Guangzhou, China) for their help collecting plant samples, and Yun-Xiao LIU (South China Botanical Garden, Chinese Academy of Sciences, Guangzhou, China) for their help with the morphology figures. This work was funded by the Main Direction Program of Knowledge Innovation of the Chinese Academy of Sciences (Grant Nos. KSCX2-EW-Q-8), and the Key Laboratory of Plant Resource Conservation and Sustainable Utilization, South China Botanical Garden, Chinese Academy of Sciences (201214ZS), and Guangdong Provincial Key Laboratory of Applied Botany, South China Botanical Garden, Chinese Academy of Sciences.

\section{Author details}

'Key Laboratory of Plant Resources Conservation and Sustainable Utilization, South China Botanical Garden, Chinese Academy of Sciences, Guangzhou 510650, China. ${ }^{2}$ University of Chinese Academy of Sciences, Beijing 100049, China. ${ }^{3}$ Department of Life Sciences, Natural History Museum, London SW75BD, UK. ${ }^{4}$ College of Landscape Architecture, Fujian Agriculture and Forestry University, Fuzhou 350002, China. ${ }^{5}$ College of Chinese Traditional Medicine, Guangzhou University of Chinese Medicine, Guangzhou 510006, China.

Received: 1 August 2014 Accepted: 27 November 2014

Published online: 05 February 2015

\section{References}

1. Lin YX: New taxa of Adiantum L. in China. Acta phytotax Sin 1980, 18:101-105 [in Chinese with English summary].

2. $X u T Q$, Zhen $Z$, Jin $Y X:$ On the distribution characteristic of the variety Adiantun reniforme var. sinense. Wuhan Bot Res 1987, 5:247-251 [in Chinese with English summary].

3. Liu YC: Flora geography of national wild conservative plants in Chongqing. Southwest China Normal Univ (Nature) 2000, 25:439-446.

4. Peng J, Long Y, Liu YL, Li XG: The rare and endangered species in Chongqing. Wuhan Bot Res 2000, 18:42-48 [in Chinese with English summary].

5. Shing KH, Wu SK: Adiantaceae. In Flora Republicae Popularis Sinicae, 3(1). Edited by Ching RC, Shing KH. Beijing: Science Press; 1990:173-216.

6. Kang $M$, Huang $H$, Jiang $M$, Lowe AJ: Understanding population structure and historical demography in a conservation context: population genetics of an endangered fern. Diversity and Distributions 2008, 14(5):799-807.

7. Pan L: Study on Growth Charaeteristics and Propagation of Adiantum reniforme var. sinense. Wuhan Botanical Garden, Chinese Academy of Science.: Wuhan; 2007.

8. Liu XQ, Wahiti GR, Chen LQ: Genetic variation in the endangered fern Adiantum reniforme var. sinense (Adiantaceae) in China. Annales Botanici Fennici 2007, 44(1):25-32.

9. Pan LQ, Ji H, Chen LQ: Genetic diversity of the natural populations of Adiantum reniforme var. sinense. Biodivers Sci 2005, 13(2):122-129 [in Chinese with English summary].

10. Lin YX: The sexual propagation and chromosome number of Adiantum reniforme L. var. sinense Y. X. Lin. Cathaya 1989, 1:143-148.

11. Wang QX, Dai XL: Spores of Polypodiales (Filicales) from China. Beijing: Science Press; 2010:10-170. 
12. Smith AR, Pryer KM, Schuettpelz E, Korall P, Schneider H, Wolf PG: A classification for extant ferns. Taxon 2006, 55:705-731.

13. Schneider H, Schuettpelz E, Pryer KM, Cranfill R, Magallón S, Lupia R: Ferns diversified in the shadow of angiosperms. Nature 2004 428(6982):553-557.

14. Schuettpelz E, Pryer KM: Fern phylogeny inferred from 400 leptosporangiat species and three plastid genes. Taxon 2007, 56:1037-1050.

15. Schuettpelz E, Schneider $H$, Huiet L, Windham MD, Pryer KM: A molecular phylogeny of the fern family Pteridaceae: assessing over all relationships and the affinities of previously unsampled genera. Mol Phylogenet Evol 2007, 44:1172-1185

16. Ruhfel B, Lindsay S, Davis CC: Phylogenetic placement of Rheopteris and the polyphyly of Monogramma (Pteridaceae s.l.): evidence from rbcL. Syst Bot 2008, 33:37-43.

17. Bouma WLM, Ritchie P, Perrie LR: Phylogeny and generic taxonomy of the New Zealand Pteridaceae ferns from chloroplast rbcL DNA sequences. Australian systematic botany 2010, 23(3):143-151.

18. Lu JM, Wen J, Lutz S, Wang YP, Li DZ: Phylogenetic relationships of Chinese Adiantum based on five plastid markers. J Plant Res 2012, 125(2):237-249.

19. Manton I: Problems of cytology and evolutions in the Pteridophyta. London: Cambridge University Press; 1950

20. Manton I, Lovis JD, Vida G, Gibby M: Cytology of the fern flora of Madeira. Bulletin of the British Museum Natural History Botany 1986, 15(2):123-161.

21. Zhang XC: Lycophytes and Ferns of China. Beijing: Peking University Press; 2012:258.

22. Doyle JJ, Doyle JL: A rapid DNA isolation procedure for small quantities of fresh leaf tissue. Phytochem Bull 1987, 19:11-15.

23. Schuettpelz E, Korall P, Pryer KM: Plastid atpA data provide improved support for deep relationships among ferns. Taxon 2006, 55:897-906.

24. Little DP, Barrington DS: Major evolutionary events in the origin and diversification of the fern genus Polystichum (Dryopteridaceae). Am J Bot 2003, 90:508-514.

25. Taberlet P, Gielly L, Pautou G, Bouvet J: Universal primers for amplification of three non-coding regions of chloroplast DNA. Plant Mol Biol 1991, 17:1105-1109.

26. Lu JM, Li DZ, Gao LM, Cheng X, Wu D: Paraphyly of Cyrtomium (Dryopteridaceae): Evidence from rbcLand trnL-F sequence data. J Plant Res 2005, 118:129-135.

27. Shaw J, Lickey EB, Beck JT, Farmer SB, Liu W, Miller J, Siripun KC, Winder CT, Schilling EE, Small RL: The tortoise and the hare II: Relative utility of 21 noncoding chloroplast DNA sequences for phylogenetic analysis. Am J Bot 2005, 92:142-166.

28. Souza-Chies T, Bittar G, Nadot S, Carter L, Besin E, Lejeune B: Phylogenetic analysis of Iridaceae with parsimony and distance methods using the plastid gene rps4. Plant Systematics and Evolution 1997, 204:109-123.

29. Hall TA: BioEdit: a user-friendly biological sequence alignment editor and analysis; 1999

30. Larkin MA, Blackshields G, Brown NP, Chenna R, McGettigan PA, McWilliam H, Valentin F, Wallace LM, Wilm A, Lopez R, Thompson JD, Gibson TJ, Higgins DG: Clustal W and Clustal X version 2.0. Bioinformatics 2007, 23(21):2947-2948.

31. Swofford DL: PAUP*: phylogenetic analysis using parsimony ( ${ }^{*}$ and other methods). version 4.0.b10. Sunderland, MA: Sinauer Associates 2002.

32. Nylander JAA: Mrmodeltest (version 2): Program Distributed by the Author. Uppsala: Evolutionary Biology Centre, Uppsala University; 2004.

33. Ronquist F, Huelsenbeck JP: MrBayes 3: Bayesian phylogenetic inference under mixed models. Bioinformatics 2003, 19:1572-1574.

34. Drummond AJ, Suchard MA, Xie D, Rambaut A: Bayesian phylogenetics with BEAUti and the BEAST 1.7. Mol Biol Evol 2012, 29(8):1969-1973.

35. Lu JM, Li DZ, Lutz S, Soejima A, Yi T, Wen J: Biogeographic disjunction between eastern Asia and North America in the Adiantum pedatum complex (Pteridaceae). Am J Bot 2011, 98(10):1680-1693.

36. Rambaut A, Drummond AJ: Tracer Version 1.5. 2007. Available online: http:// beast.bio.ed.ac.uk/Tracer (accessed on 21 December 2011).

37. Harris JG, Harris MW: Plant identification terminology: An illustrated glossary. Beijing: Science Press; 2001:1-302

38. Sim TR: Ferns of South Africa. CUP Archive. 1915. Available online: http:// www.clarkes.co.za/book/ferns-of-south-africa.

39. Sun H, Li ZM: Evolution and development of the Tethys flora in China after uplift of Tibet Plateau. Adv Earth Sci 2003, 18(6):852-862.

40. Li JJ: Landform evolution and Asian monsoon of the Qing hai -Xi zang Plateau. Marine Geology and Quaternary Geology 1999, 19(1):1-9.
41. Zhu DG, Meng XG, Shao ZG, Yang CB, Han JE, Yu J, Meng QW, Lü RP: The Formation and Evolution of Zhada Basin in Tibet and the Uplift of the Himalayas. Acta geoscientica sinica 2006, 27(3):193-200.

42. Peng H: Discussion about the impact of the Qinghai-Tibet Plateau's uplift on China climate. Geographical Research 1989, 8(3):85-92.

43. Barrington DS: Ecological and historical factors in fern biogeography. J Biogeogr 1993, 20:275-280.

44. Smith AR: Phytogeographic principles and their use in understanding fern relationships. J Biogeogr 1993, 20:255-264.

45. Wolf PG, Schneider H, Ranker TA: Geographic distributions of homosporous ferns: Does dispersal obscure evidence of vicariance? J Biogeogr 2001, 28:263-270.

46. Schmincke HU: Volcanic and chemical evolution of the Canary Islands. In Geology of the Northwest African continental margin. Edited by von Rad U, Hinz K, Sarnthein M, Seibold E. Berlin Heidelberg New York: Springer; 1982:273-306

47. Carracedo JC: The Canary Islands: an example of structural control on the growth of large oceanic-island volcanoes. Journal of Volcanology and Geothermal Reaearch 1994, 60:225-241.

48. Carracedo JC: A simple model for the génesis of large gravitational landslide hazards in the Canary Islands. In Volcano Instability on the Earth and Other Planets, Geol. Soc. Lond. Spec. Publ, Volume 110. Edited by McGuire WJ, Jones AP, Neuberg J. ; 1996:125-135.

49. Abratis M, Schmincke HU, Hansteen TH: Composition and evolution of submarine volcanic rocks from the central and western Canary Islands. Int J Earth Sci (Geol Rundsch) 2002, 91:562-582.

50. Stillman CJ: Giant Miocene landslides and the evolution of Fuerteventura, Canary Islands. J Volcanol Geotherm Res 1999, 94:89-104.

\section{Submit your next manuscript to BioMed Central and take full advantage of:}

- Convenient online submission

- Thorough peer review

- No space constraints or color figure charges

- Immediate publication on acceptance

- Inclusion in PubMed, CAS, Scopus and Google Scholar

- Research which is freely available for redistribution 